\title{
Los titulares de la potestad sancionadora. Los entes locales
}

\author{
María Teresa Carballeira Rivera
}

Sumario: I. INTRODUCCIÓN. II. LA SITUACIÓN DE PARTIDA: LOS ENTES LOCALES CARECEN DE POTESTAD SANCIONADORA AUTÓNOMA. III. LA RESOLUCIÓN DE LA TENSIÓN AUTONOMÍA LOCAL VS LEGALIDAD SANCIONADORA. 1. Soluciones aportadas por la doctrina y el legislador. 2. Soluciones aportadas por la jurisprudencia. IV. EL NUEVO TÍTULO XI DE LA LEY BÁSICA DE RÉGIMEN LOCAL. V. CRÍTICAS Y CONTRACRÍTICAS AL MODELO SANCIONADOR LOCAL. 1. Sobre la heterogeneidad normativa. 2. Sobre la legalidad formal. 3. Sobre la legalidad material. VI. ALGUNAS CUESTIONES SOBE EL ACTUAL EJERCICIO DE LA POTESTAD SANCIONADORA LOCAL. VII. UN PASO MÁS HACÍA EL RECONOCIMIENTO DE LA AUTONOMÍA LOCAL: LA STS DE 20 DE DICIEMBRE DE 2007. EL PODER DE NORMACIÓN Y LA POTESTAD IMPLÍCITA DE SANCIÓN. VIII. LA CONCRETA ATRIBUCIÓN DE LA POTESTAD SANCIONADORA EN EL ÁMBITO LOCAL.

\section{INTRODUCCIÓN}

El ejercicio de la potestad sancionadora local en el Estado constitucional se podría resumir como un intento de superación permanente de las tensiones generadas entre el principio de autonomía local (art. 137 CE) y el principio de legalidad que rige la articulación de la potestad (art. $25 \mathrm{CE}$ ). Este recorrido siempre ha estado presidido por un objetivo claro: buscar una fórmula dogmática y legal que sin vulnerar el art. 25 CE permita a los entes locales ejercer con plena libertad y responsabilidad su histórica potestad sancionadora de la que son titulares, tal como ha quedado reconocida en el art. 4.1.f) LBRL.

Como es sobradamente conocido, la Constitución española dispone en el citado art. 25.1 que "nadie puede ser condenado o sancionado por acciones u omisiones que

1 Profesora Titular de Derecho Administrativo. Universidad de Santiago de Compostela. 
en el momento de producirse no constituyan delito, falta o infracción administrativa, según la legislación vigente en aquel momento".

Rápidamente, el Tribunal Constitucional se apresuró a definir lo que habría de entenderse por "legislación vigente" con un doble objetivo: en primer lugar, para cortar de raíz la dinámica de actuación precedente del poder administrativo en el ejercicio de la postestad sancionadora que permitía, en muchos casos, la imposición de sanciones que iban más allá de la mera multa, sin respaldo legal alguno e incluso sin un procedimiento administrativo que garantizase los derechos del interesado. $Y$, en segundo lugar, para asentar el derecho fundamental a la legalidad sancionadora creando un blindaje de seguridad en los ámbitos limitativos de la libertad individual que obligatoriamente debía traducirse en la exigencia de predeterminación normativa de las conductas ilícitas y de las sanciones correspondientes.

El resultado fue la construcción de una laudable garantía formal y material según la cual las normas sancionadoras han de tener rango de ley y definir taxativamente los supuestos de infracción y la imposición de sanciones. Así se estableció, por ejemplo, en la STC 305/1993, de 25 de octubre, al señalar que "el art. 25.1 CE obliga al legislador a regular por sí mismo los tipos de infracciones administrativas y las sanciones que le sean de aplicación, sin que sea posible que, a partir de la Constitución, se puedan tipificar nuevas infracciones ni introducir nuevas sanciones o alterar el cuadro de las existentes por una norma reglamentaria cuyo contenido no esté suficientemente predeterminado o delimitado por otra con rango de Ley" (FJ 3).

No obstante, el propio Tribunal reconoció que la incorporación de la regla nullum crimen nulla poena sine lege al ámbito administrativo no podía ser interpretada de la misma forma que en el ámbito penal: al rigor propio de éste ámbito habrá de oponerse la flexibilización en el ámbito administrativo. Y ello igualmente por varias razones: "tanto por razones que atañen al modelo constitucional de distribución de las potestades públicas como por el carácter en cierto modo insuprimible de la potestad reglamentaria en determinadas materias, o bien, por último, por exigencias de prudencia o de oportunidad" (STC 42/1987, de 7 de abril, FJ 2).

La penetración del reglamento en el diseño legal de la potestad sancionadora de la Administración es posible. Ahora bien, su encaje será constitucionalmente válido siempre y cuando se observen unos límites convergentes: la necesaria habilitación legal previa y la imposibilidad de una regulación reglamentaria independiente:

“En todo caso, el artículo 25.1 CE exige la necesaria cobertura de la potestad sancionadora de la Administración en una norma de rango legal habida cuenta del carácter excepcional que presentan los poderes sancionatorios en manos de la Administración (SSTC 2/1988, de 21 de enero, F. 9, y 305/1993, de 25 de octubre, F. 3). De ahí que la reserva de Ley en este ámbito tendría una eficacia relativa o limitada (STC 177/1992, de 2 de noviembre, F.2), que no excluye la colaboración reglamenta- 
ria en la propia tarea de tipificación de las infracciones y atribución de las correspondientes sanciones, pero sí que tales remisiones hicieran posible una regulación independiente y no claramente subordinada a la Ley" (STC 52/2003, de 17 de marzo, FJ 7).

Sobre este escenario jurídico debe operar la ordenanza local en tanto que norma local superior aunque de rango reglamentario y único medio de tipificación de infracciones y establecimiento de sanciones administrativas de que disponen las entidades locales.

Muchos y variados han sido los intentos doctrinales y legales realizados para superar esta situación. Uno de los últimos ha sido la incorporación a la LBRL del Título XI (arts. 139 a 141) a través de la Ley 57/2003, de 16 de diciembre, de medidas para la modernización del Gobierno local.

Sobre la especificidad de esta problemática y el análisis de las soluciones aportadas dedicaremos las siguientes páginas de este trabajo.

\section{LA SITUACIÓN DE PARTIDA: LOS ENTES LOCALES CARECEN DE POTESTAD SANCIONADORA AUTÓNOMA}

Siguiendo el trazado anteriormente descrito, para que un ente pueda ejercer el ius punendi del Estado se exigen dos requisitos: el primero que tenga atribuida expresamente el ejercicio de la potestad sancionadora y, el segundo, que tanto las infracciones como las sanciones estén previstas detalladamente en una norma con rango formal de ley.

El primero de los requisitos viene recogido en el art. 127.1 de la LRJ-PAC que desarrolla los principios constitucionales del art. 25 CE y es aplicable también a las entidades locales (art. 2 de la misma Ley). Según aquél, "la potestad sancionadora de las Administraciones públicas, reconocida por la Constitución, se ejercerá cuando haya sido expresamente atribuida por una norma con rango de ley". Tal extremo se cumplimenta debidamente en el art. 4.1.f) de la LBRL que atribuye a los entes locales, municipio, provincia e isla, la potestad sancionadora. Ello no impide, sin embargo, que otras leyes, estatales o autonómicas, atribuyan idéntica potestad a otros entes locales, sean o no territoriales.

El otorgamiento de este poder guarda estrecha relación con el principio de autonomía local recogido en el art. 137 CE cuya lógica no requiere mayores explicaciones. Baste decir que, siendo como son entes territoriales y base organizativa del Estado dedicados a la consecución de los intereses propios, la atribución de esta potestad es inherente al poder de ordenación de los asuntos locales, esto es, "se constituye como un poder adjetivo necesario para asegurar el cumplimiento por parte de todos los 
ciudadanos de las normas y decisiones emanadas por las Entidades locales"2. No obstante, como nos recuerda la jurisprudencia, la declaración efectuada por la LBRL alude únicamente a la titularidad local del poder sancionador, no al poder para tipificar concretas infracciones y sanciones (STS de 6 de febrero de 1996).

De ahí el segundo de los requisitos, esto es, la necesaria habilitación legal previa y el contenido mínimo de esta habilitación para ejercer la función sancionadora. Aquí radica el núcleo de la polémica que se ha venido arrastrando hasta hace bien poco y que aún coletea en el espacio local.

La interpretación constitucional del art. 25 CE exige, como se vio, reserva de ley formal para la tipificación de infracciones y sanciones. Habida cuenta que los entes locales carecen potestad legislativa plena, la única posibilidad que resta es que sea la ley, estatal o autonómica, la que reuniendo las características de escrita, previa y cierta, les confiera dicha habilitación para poder actuar a través de una norma reglamentaria como es la ordenanza local.

De entrada, pues, la potestad sancionadora, pese a ser conferida a los entes locales sin restricción alguna, se manifiesta como un poder mediatizado por el legislador de los otros niveles territoriales, un poder carente de ejercicio autónomo. Consiguientemente, la titularidad del mismo no implica su ejercicio pleno en el ámbito de las competencias locales sino más bien un ejercicio interceptado en aras de la garantía formal y material de la legalidad sancionadora. La potestad sancionadora de los entes locales se visualiza así como una facultad latente, un poder potencial que sólo se manifiesta cuando la ley abre paso a la acción punitiva de las entidades locales. Mientras tanto, la capacidad del ente local de decidir con plena autonomía y responsabilidad sobre sus competencias en los términos expresados por el art. 7 LBRL permanece congelada.

Tal situación supone cuatro órdenes de problemas si la enfrentamos con el principio de autonomía local. Primeramente, la supeditación permanente de las entidades locales a las instancias territoriales superiores para el ejercicio de esta potestad sobre sus competencias propias; en segundo lugar, el carácter semipleno o de mera atribución de titularidad de la potestad sancionadora conferida por el art. 4.1.f) LBRL; en tercer lugar, la minusvaloración de la autonomía territorial que en este extremo guardan mayores concomitancias con la autonomía funcional propia de la Administración instrumental que con la predicada por el art. 137 CE; y, en cuarto lugar, la asimetría, como ha destacado en su día Sanz Gandasegui, entre las competencias atribuidas a las entidades locales y el campo de actuación de la potestad sancionadora para hacerlas valer ${ }^{3}$.

2 Sanz Gandasegui, F, “El ejercicio de la potestad sancionadora por la Administración Local”, en Manual de Derecho Administrativo sancionador, (De Fuentes Bardají, dir), Ministerio de Justicia-Thomson Aranzadi, Navarra, 2009, pág. 664. 


\section{LA RESOLUCIÓN DE LA TENSIÓN AUTONOMÍA LOCAL VS LEGALIDAD SANCIONADORA}

\section{Soluciones aportadas por la doctrina y el legislador}

Algunos de los inconvenientes descritos se suavizaron a través de la emanación de leyes sectoriales que, a la par que atribuían competencias a los entes locales, significadamente a los municipios, tipificaban los ilícitos administrativos y los tipos de sanciones correspondientes. Tal es el caso del ejercicio de la potestad sancionadora en materia de protección de la seguridad ciudadana prevista en el art. 29.2 de la Ley Orgánica 1/1992, de 21 de febrero, que declara la competencia de los Alcaldes para imponer las sanciones de suspensión de la autorizaciones o permisos que se hubiesen concedido y la imposición de multas frente a aquellas infracciones graves o leves dispuestas en el art. 26 de la Ley en materia de espectáculos públicos y actividades recreativas, tenencia ilícita y consumo público de drogas, entre otras. O la regulada en la Ley 22/1988, de 28 de julio, de costas, que en su art. 99 habilita a los Alcaldes para la imposición de multa frente a las actuaciones ilícitas realizadas sobre materias de competencia municipal en el espacio costero. $O$, en fin, en materia de tráfico, la atribución al municipio de competencias sancionadoras en la materia ex art. 7 y la habilitación concedida a los Alcaldes para imponer sanciones por infracción de normas de circulación cometida en vías urbanas, según dispone el art. 68 del Real Decreto Legislativo 339/1990, de 2 de marzo. En todos estos casos, se contiene un cuadro detallado de infracciones y sanciones y la correspondiente habilitación a la entidad municipal a través de su órgano de representación para ejercer la potestad sancionadora.

Sin embargo, la ley sectorial aún en su magnanimidad no es capaz de salvar todas las situaciones en las que está implicado el ejercicio de la potestad sancionadora local. En algunos casos, no contempla con grado suficiente de detalle la tipificación de conductas punibles en el ámbito local, ya sea por la casuística que encierran ya sea por falta de previsión. En otros, sencillamente no desciende a la arena local porque o bien las materias allí tratadas no son de competencia local o son de competencia eminentemente local.

Resta, por tanto, un paquete nada despreciable de asuntos en los que el ente local se ve desapoderado para ejercer el poder de coacción porque falta la habilitación legal previa o la tipificación correspondiente. Son, por regla general, actividades que afectan directamente a la gestión de servicios y bienes locales o al buen orden social de la comunidad vecinal. La litigiosidad da buena muestra de esta realidad cuando se impugnan ordenanzas locales que contravienen el principio de legalidad sancionadora al tipificar conductas y sanciones sin cobertura legal tales como la expedición de bebidas para el consumo fuera del local (STS de 3 de diciembre de 2003), la revocación de licencias por ocupación ilícita de los bienes demaniales locales (STS de 26 de marzo de 2001), la tenencia y circulación de animales de compañía que afectan a la seguridad de las personas (STS 25 de mayo de 2004), la perturbación de la actividad de uso público de viales y calles (STSJ Madrid 624/2006, de 16 de marzo) o 
bien hay que introducirlas a pie forzado en otros títulos como la instalación de antenas de telefonía móvil (STSJ Andalucía 416/2008, de 31 de marzo).

Así las cosas, y vista la urgencia de dar una solución conciliadora a sendos principios de legalidad y autonomía local, las propuestas doctrinales, jurisprudenciales y normativas no se dejaron esperar.

La primera de ellas consistió en apelar a los arts. 55 y 59 del Real Decreto Legislativo 781/1986, de 18 de abril por el que se aprueba el Texto Refundido de las disposiciones vigentes sobre régimen local. Se establece en uno que "en la esfera de su competencia las entidades locales podrán aprobar Ordenanzas y Reglamentos y los Alcaldes dictar bandos. En ningún caso contendrán preceptos opuestos a las leyes". Y en el otro, que las sanciones por infracción de ordenanzas ha de consistir en multas regulando a tal efecto una escala de sanciones establecidas según la población del municipio.

Se trató de alumbrar por esta vía la innecesariedad de habilitación legal expresa para el ejercicio de la potestad sancionadora local a través de las ordenanzas pues este marco jurídico era de por sí suficiente y contenía una habilitación legal que permitía al ente local tipificar válidamente infracciones y sanciones siempre y cuando no contravinieran las leyes y se ajustase a las prescripciones allí establecidas. En definitiva, una suerte de vinculación negativa a la legalidad pues la única limitación impuesta por el precepto era moverse en el marco de la ley y no conforme a ley.

Con posterioridad, el Real Decreto de 4 de agosto de 1993 por el que se dicta el Reglamento del procedimiento para el ejercicio de la potestad sancionadora, intentó mediar en la contienda de principios jugando a favor de la autonomía local. Según su art. 2.2, "las entidades que integran la Administración local, cuando tipifiquen como infracciones hechos y conductas mediante ordenanzas y tipifiquen como infracción de ordenanza el incumplimiento total o parcial de las obligaciones o prohibiciones establecidas en las mismas, al aplicarlas deberán respetar en todo caso las tipificaciones previstas en la ley". Dicho artículo hay que interpretarlo a la luz de la Exposición de Motivos del propio Reglamento que aún expresándose en términos ambiguos, intenta afianzar la idea de la ordenanza como norma de rango suprarreglamentario o cuasi de ley al subrayar su crucial papel como "instrumento adecuado para atender a esta finalidad y para proceder en el marco de sus competencias a una tipificación de infracciones y sanciones", sin que, por lo demás, consiga despegarse de las exigencias del derecho fundamental. Idea que de alguna manera refuerza también su Disposición Adicional única cuando proclama la vigencia de las ordenanzas sancionadores locales que cumplan con los requisitos del citado art. 2.2.

A tenor de una solvente doctrina presidida por García de Enterría ${ }^{4}$, esta estrategia normativa para salvar la falta de cobertura legal de las ordenanzas locales adolece 4 García de Enterría, E., “La problemática puesta en aplicación de la LRJ-PAC: el caso del Real
240 Decreto 1389/1993, de 4 de agosto, que aprueba el Reglamento del procedimiento para el ejercicio de la 
de un doble defecto ya que ni tal habilitación se puede efectuar desde un reglamento ejecutivo como es el aludido ni puede desprenderse de la literalidad del precepto que la ordenanza colma suficientemente las exigencias del art. 25 CE en lo que atañe a la legalidad sancionadora.

La debilidad de las respuestas legales hizo que las miradas se dirigiesen hacia otros derroteros jurídicos. Algunas propuestas encomiables en sede doctrinal ${ }^{5}$ como $^{\circ}$ la elaborada por Nieto, apostaron por desvincular la Ordenanza de las relaciones Leyreglamento dándole un estatus especial. En este sentido señala el autor que "cuando se trata de entes corporativos e institucionales, como no existen leyes propias de ellos emanadas, sería ilógico exigir este requisito y por ello el Tribunal pasa por alto la reserva legal en las normas Deontológicas. Pues exactamente lo mismo sucede con las Ordenanzas" ". Argumentación que cobra más fuerza si cabe al enfatizar el origen democrático-representativo del órgano del que emanan?.

En la misma línea pero más cercanas en el tiempo son las apuestas realizadas por Ortega cuando defiende la ordenanza local como expresión normativa del ordenamiento local que se relaciona con los legislativos estatal y autonómico no en función del principio de separación de poderes sino en aplicación del principio de autonomía ordinamental de un Estado políticamente descentralizado. Por eso, señala el autor, "debe construirse dogmáticamente una diferente relación entre la Ley y la ordenanza local, de la existente entre Ley y reglamento, de forma que no sean de aplicación mimética los principios de jerarquía y reserva material y formal de las fuentes jurídicas, propios de una teorización de la división de poderes, sino que estas relaciones entre fuentes del Derecho se construyan desde una nueva óptica de relaciones interordinamentales".

Desde otro ángulo, Carro considera que el punto focal debe situarse en la cláusula general de competencia municipal contenida en el art. 25.1 LBRL. Entiende el autor que al operar ésta como título legislativo habilitante de la normativa municipal en el ámbito por ella diseñado, podría al mismo tiempo desempeñar esta misma función en materia sancionadora dado que la potestad sancionadora ha de considerarse como un poder implícito de las corporaciones locales, derivado de las correspondientes atribuciones competenciales?.

potestad sancionadora”, REDA, n 80, 1993, pág. 664 y ss. También en García Gómez de Mercado, F., Sanciones Administrativas, Comares, Granada, 2004, pág. 43.

5 Un resumen de las distintas posturas doctrinales puede encontrarse en Gallardo Castillo, M.J, Los principios de la potestad sancionadora. Teoría y práctica, lustel, Madrid, 2008, págs. 64 y ss. También, Tolivar Alas, L., "El ejercicio de la potestad sancionadora por los Municipios”, Revista de estudios locales, julio, 2002, págs. 233 y ss.

6 Nieto, A., Derecho Administrativo sancionador, Tecnos, Madrid, 2004, pág. 123.

7 Baño León, J.M., Reserva de Ley y potestad reglamentaria, Cívitas, Madrid, 1991, pág. 152.

8 Ortega Alvarez, L., "El sistema competencial propuesto en el anteproyecto de ley básica del gobierno y de la administración local”, en Reforma y retos de la Administración Local (Parada y Fuentetaja, dir.), Marcial Pons, Barcelona, 2007, pág.117.

9 Carro Fernández-Valmayor, J.L., "Sobre la potestad sancionadora municipal”, Cuadernos de Derecho Local, n²6, 2004, pág. 139. 


\section{Soluciones aportadas por la jurisprudencia}

Sea como fuera, lo cierto es que abundan los motivos y razones para dar una salida airosa a este debatido punto de la potestad sancionadora local. En apoyo de esa búsqueda vinieron igualmente algunas sentencias del Tribunal Constitucional, suficientemente comentadas por la doctrina jurídica pero que aún así merecen una escueta mención. La STC 132/2001, de 8 de junio, marcó un punto de inflexión. Por lo que ahora interesa, se debatía allí la suspensión temporal de una licencia de autotaxis impuesta por el Ayuntamiento de Madrid de acuerdo con la ordenanza madrileña del taxi. El recurrente acudió en amparo ante el Tribunal Constitucional demandando protección al derecho fundamental a la legalidad sancionadora, aduciendo, entre otras cuestiones, falta de cobertura legal de la norma local para la imposición de la sanción.

Frente a ello, el Tribunal comienza por asumir uno de los criterios más defendidos por la doctrina cual es la no aplicación de la jerarquía normativa a las ordenanzas locales. De modo que la limitación reglamentaria impuesta al hilo de la aplicación del principio de legalidad sancionadora "está enunciada para definir la relación entre las leyes y los reglamentos, por lo que necesita de ulteriores precisiones cuando se trata de definir la colaboración normativa de las ordenanzas municipales" (FJ5).

La primera precisión sobre cuál es el papel a jugar por la ordenanza en esta materia se efectúa a partir de la laxitud con que se entendió en su momento la reserva de ley en materia de establecimiento de tributos locales. Tomando como base la flexibilidad allí admitida, entiende el Tribunal que cabría aplicarla al ámbito de la potestad sancionadora:

\footnotetext{
"También la exigencia de ley para la tipificación de infracciones y sanciones ha de ser flexible en materias donde, por estar presente el interés local, existe un amplio campo para la regulación municipal y siempre que la regulación local la apruebe el Pleno del Ayuntamiento [... L La flexibilidad alcanza al punto de no ser exigible una definición de cada tipo de ilícito y sanción en la ley" (FJ 6).
}

Desde este nuevo prisma exegético, la doctrina constitucional establece las siguientes acotaciones a la relajación del principio de legalidad sancionadora:

a) La mera atribución por ley de competencias a los municipios, conforme al art. 25 LBRL, no implica la autorización para que cada municipio tipifique por completo y según su propio criterio las infracciones y sanciones administrativas en dichas materias. No hay correspondencia entre la facultad de regular un ámbito material de interés local y el poder para sancionar.

b) Corresponde a la ley la fijación de los criterios mínimos de antijuridicidad con-

242 forme a los cuales cada Ayuntamiento puede establecer los tipos de infracciones. 
c) Estos criterios mínimos legales no tienen por qué consistir en la fijación de tipos genéricos de infracciones sino que basta el establecimiento de meras orientaciones.

d) En cuanto al establecimiento de sanciones, tampoco se exige que la ley establezca una clase específica de sanción para cada grupo de ilícitos, sino que basta una relación de posibles sanciones que cada ordenanza municipal puede luego concretar.

e) Por último, la norma local ha de estar revestida del elemento democrático, de manera que sólo cuando ésta sea emanada por el Pleno de la Corporación local cabe aplicar la excepción al principio de legalidad sancionadora comentado.

Así pues, frente a la rigidez impuesta en sentencias como la 42/1987 según la cual "la simple habilitación a la Administración, por normas de rango legal vacía de todo contenido material propio, para la tipificación de los ilícitos administrativos y las correspondientes consecuencias sancionadoras" (FJ 2), no es válida se impone el reconocimiento de un estatus especial a la ordenanza local en tanto que norma primaria del ordenamiento local como medio idóneo para garantizar el principio de tipicidad bajo el paraguas de una ley que de manera formal -más que material- cubra las exigencias constitucionales de este derecho fundamental. Existe una reserva de ley relativa. La seguridad jurídica del ciudadano, fundamento último del principio de legalidad en el ámbito sancionador, no se ve afectado por esta suerte de remisión genérica y orientativa que efectúa la ley a la norma local.

Este cambio de dirección jurisprudencial tiene su razón de ser y desde la perspectiva de la autonomía local se justifica sobradamente. En efecto, tal como el mismo Tribunal Constitucional nos recordaba en la STC 240/2006, de 20 de julio, la autonomía local es esencialmente "el derecho de la comunidad local a participar a través de órganos propios en el gobierno y administración de cuantos asuntos le atañen, graduándose la intensidad de esta participación en función de la relación existente entre los intereses locales y supralocales dentro de tales asuntos o materias. Para el ejercicio de esa participación en el gobierno y administración en cuanto les atañe, los órganos representativos de la comunidad local ha de estar dotados de las potestades sin las que ninguna actuación autonómica es posible" (FJ 8).

En definitiva, autogobierno local y ejercicio pleno de potestades son dos elementos de una ecuación indisoluble. Como recuerda la Carta Europea de la autonomía local, las entidades locales gozan de libertad plena para ejercer su iniciativa en toda materia que no esté excluida de sus competencias y atribuida a otra autoridad (Art. 4.2). Y esa libertad plena implica "capacidad efectiva", "ordenar y gestionar en beneficio de sus habitantes" y "propia responsabilidad". Si una de las partes se devalúa, ya sea por interdicción del legislador, ya sea por imposibilidad de su ejercicio, la otra corre el mismo destino. $Y$ dado que el ejercicio de la potestad sancionadora se constituye en un elemento indispensable para la ordenación y gestión de los asuntos locales, no puede por más que afirmarse que cualquier limitación a ésta se convierte en una limitación a la autonomía reconocida en los arts. 137 y 140 de la Constitución. 
A este pronunciamiento jurisprudencial le siguieron otros de similar factura y contenido. La STC 232/2006, de 17 de julio, dictada a propósito también de una competencia propia local como es la regulación del servicio de vehículos de alquiler con aparato taxímetro, señaló que "la exigencia de Ley para la regulación de las infracciones y sanciones en las ordenanzas municipales, siempre que se aprueben por el Pleno del Ayuntamiento, ha de ser flexible, aunque esta flexibilidad no sirve, con todo, para excluir de forma tajante la exigencia de la Ley" (FJ 4). En la misma línea se mueve la STC 16/2004, de 23 de febrero, que resuelve un litigio sobre contaminación acústica.

El Tribunal Supremo, con anterioridad a estos pronunciamientos del Tribunal Constitucional mantuvo una postura vacilante. En unos casos adoptó una posición cautelosa conforme a la cual la ordenanza sancionadora precisa siempre de una norma legal de cobertura, normalmente sectorial, en la que se regulen las infracciones y sanciones (SSTS de 25 de mayo de 1993, 13 de octubre de 1995, 6 de noviembre de 1995, 6 de febrero de 1996, 29 de mayo de 1998), y en otros acogió posturas más abiertas como la de las potestades sancionadores implícitas en las competencias atribuidas por la LBRL (SSTS de 2 de abril de 1991 y 16 de julio de 1998) ${ }^{10}$.

Tras la STC 132/2001 y haciéndose eco de esta nueva corriente hermenéutica, apuró aún más la resolución de la cuestión llegando a declarar que "las ordenanzas locales pueden establecer válidamente infracciones y sanciones con tal de que exista una norma con rango de Ley que establezca al menos unos principios generales reguladores de la materia". Incluso, puede efectuarse "aunque no exista Ley estatal o autonómica previa, siempre que se ejerzan las potestades administrativas en materia de competencia típica de los Ayuntamientos" (STS de 3 de diciembre de 2003, FJ 3). Basta con los preceptos generales establecidos en los arts. 55 y 59 TRRL para poder tipificar validamente infracciones y sanciones de carácter pecuniario siempre que al hacerlo no se contravengan las leyes vigentes, no exista ley sectorial sobre la materia y los Ayuntamientos actúen en ejercicio de competencias propias que lleven anejas potestades implícitas de regulación (STS de 29 de septiembre de 2003, FJ 7).

Consecuentemente, la tensión entre sendos principios ha de resolverse "de un modo favorable al principio de autonomía local" cuando se trate de competencias nucleares de los entes locales que llevan implícitas potestades de ordenamiento o de organización (STS de 25 de mayo de 2004, FJ 6).

Con todo y habida cuenta de que lo que está en pugna en el escenario local son, de una parte, la regulación de los ámbitos de libertad que corresponden al ciudadano a través de la voluntad de sus representantes y, de otra, el autogobierno local y más

10 Un estudio de este aspecto en la jurisprudencia se ofrece en Cano Campos, T., "Derecho Administrativo sancionador”, Revista General de Derecho Administrativo, n5, 2004. También en IUSTEL, págs. 1 y ss. 
precisamente la convivencia ciudadana, cualquier solución que no preserve el equilibrio de sendos valores constitucionales está abocada al fracaso. Claramente se ve que hay dos bienes jurídicos en lid de igual importancia, uno de carácter individual y otro de carácter social o colectivo, que precisan de tutela y protección.

De ahí que la jurisprudencia constitucional no llegue a dar una solución salomónica y pese a afirmar una cierta emancipación de la ordenanza respecto de la categoría del reglamento, no se atreve a llevar a cabo su equiparación con la ley por muy emanación de la voluntad de los representantes locales que sea. En cierto modo, el Tribunal hace un guiño a la autonomía local sin despegarse de los principios de la jerarquía normativa. Ello explica porqué el reconocimiento de un régimen flexible para el ámbito local no desemboca en un ejercicio pleno, responsable y autónomo de la potestad sancionadora en este espacio territorial. A corroborar lo dicho vienen las segundas lecturas que de la reserva de ley efectuó el Alto Tribunal en numerosas sentencias.

En efecto, la reserva de ley con no operar de manera tan rigurosa frente a la ordenanza, no puede transformarse en una ley en blanco. Existe un núcleo central de la materia reservado constitucionalmente al legislador, estatal o autonómico, que debe cumplimentar para que el derecho fundamental a la legalidad sancionadora no sufra de manera intolerable. Ese núcleo es el relativo a "la predeterminación de las infracciones, de las sanciones y de la correspondencia entre ambas", conforme a la propia terminología usada por el Tribunal (STC 16/2004, de 23 de febrero, FJ 5). Se trataría de una especie de andamiajes legales sobre los que asentar el desarrollo normativo local que cumplan la doble función de limitación y directriz.

Consiguientemente, la imposición de un tipo de sanción no contemplado en una Ley conlleva la inconstitucionalidad de la resolución administrativa (STC 232/2006, de 17 de julio). La búsqueda de habilitación legal de una ordenanza para tipificar hechos ilícitos en una norma con rango de ley cuyo objeto de regulación pueda ser concomitante pero no idéntico con el previsto allí también sería causa de vulneración constitucional (STC 25/2004, de 26 de febrero). O, en fin, el establecimiento de infracciones que no parta de unos criterios de antijuridicidad establecidos por la Ley que sirvan de límite al ente local en el uso de su potestad normativa, violarían igualmente el art. 25 CE.

\section{EL NUEVO TíTULO XI DE LA LEY BÁSICA DE RÉGIMEN LOCAL}

Tal como hemos ido desgranando, las posturas en torno al ejercicio de la potestad sancionadora local podrían clasificarse en tres grandes hitos jurídicos según las etapas de su evolución: a) la adhesión incondicional al principio de legalidad reconocido en el art. 25 CE; b) la flexibilización de esa visión estricta del principio de legalidad por vía jurisprudencial; y, c) la superación y acoplamiento del principio de legalidad sancionadora al principio de autonomía local por vía normativa. 
Respecto de esta última, el protagonismo indiscutible ha de atribuirse a la Ley 57/2003, de 16 de diciembre, de medidas para la modernización del gobierno local, que con la introducción de un nuevo Título XI en la LBRL, "Tipificación de las infracciones y sanciones por las Entidades locales en determinadas materias", intentó zanjar la polémica arrastrada en tres artículos. Asimismo, introdujo incisos en los arts. 127.1 y 129.1 de la LRJ-PAC para adaptarlos a la vigente legislación ${ }^{11}$.

Según se relata en su Exposición de motivos, el Título pretende colmar la laguna legal existente en la materia, significadamente, en aquellas esferas en las que la potestad sancionadora local no encuentre apoyatura en la legislación sectorial. Para ello, establece "criterios de tipificación de las infracciones y las correspondientes escalas de sanciones para que las funciones de esta naturaleza se desarrollen adecuadamente, de acuerdo con las exigencias del principio de legalidad adaptadas a las singularidades locales, y siempre en defensa de la convivencia ciudadana en la defensa de los asuntos de interés local y de los servicios y el patrimonio municipal”.

El art. 139 LBRL representa el aspecto formal del principio de legalidad sancionadora. Recoge la habilitación legal para dar entrada a la norma local y regula su ámbito de aplicación disponiendo que "para la adecuada ordenación de las relaciones de convivencia de interés local y del uso de sus servicios, equipamientos, infraestructuras, instalaciones y espacios públicos, los entes locales podrán, en defecto de normativa sectorial específica, establecer los tipos de infracciones e imponer sanciones por el incumplimiento de deberes, prohibiciones o limitaciones contenidos en las correspondientes ordenanzas, de acuerdo con los criterios establecidos en los artículos siguientes".

Varias son, pues, las notas que enmarcan a este apoderamiento para la tipificación sancionadora local y que podríamos concretar en las siguientes atendiendo al espíritu de la Ley y la jurisprudencia constitucional:

a) La regulación tiene carácter subsidiario. No debe de existir normativa sectorial sobre la materia pues en ese caso gozaría de aplicación preferente.

b) Su ámbito material de actuación se circunscribe a determinados asuntos de competencia eminentemente local y en concreto a los relacionados con el orden social, los bienes y los servicios locales.

c) La regulación va dirigida a todos los entes locales garantizados por la Constitución y no exclusivamente a los municipios.

11 Una visión general de la reforma la podemos encontrar en Rebollo Puig, M., e Izquierdo Carrasco, M., Comentarios a la Ley reguladora de las Bases del Régimen Local, Tirant lo Blanc, Valencia, 2006. Arias 246 Martínez, A., "Tipificación de las infracciones y sanciones por las entidades locales”, en La modernización 
d) Los artículos de la LBRL no son de aplicación directa a los ciudadanos sino que operan como una Ley marco que fija los criterios así llamados de antijuridicidad que habrá de desarrollar la normativa local.

e) La norma local de desarrollo de la potestad sancionadora deberá ser dictada por el órgano representativo de la entidad. El reglamento y la ordenanza son las únicas que tienen cabida en esta materia.

f) Por último, la potestad sancionadora, como no podía ser de otra manera, tiene un fin instrumental respecto de la actividad de normación de asuntos locales y es el de asegurar el cumplimiento de los contenidos de la ordenanza.

El art. 140 LBRL constituye el complemento indispensable de la habilitación anterior al fijar los contenidos del principio de legalidad material. Tipifica las conductas sancionables y clasifica las infracciones en muy graves, graves y leves.

El precepto se detiene en definir los tipos de infracciones muy graves sobre los bienes jurídicos aludidos a través de la descripción de una serie de hechos y la intensidad o trascendencia del mismo. Se consideran acciones punibles muy graves en materia de convivencia ciudadana, la perturbación relevante que afecte de manera grave, inmediata y directa a la tranquilidad o al ejercicio de derechos legítimos de otras personas, al normal desarrollo de actividades de toda clase conformes con la normativa aplicable o la salubridad y ornato públicos.

Respecto de los servicios públicos, se califican como muy graves el impedimento del uso por terceros usuarios y la grave y relevante obstrucción al normal funcionamiento. $Y$ en relación con los equipamientos, instalaciones, infraestructuras y espacios públicos, los actos de deterioro grave y relevante y el impedimento del uso por terceros.

Esta tipificación contrasta, sin embargo, con la libertad dejada al legislador local a la hora de determinar las conductas punibles graves o leves. Como ya han puesto de manifiesto suficientemente algunos autores ${ }^{12}$, se trata de una categoría residual donde el único criterio aportado por la LBRL para la clasificación de la infracción depende de la "intensidad" de la perturbación o daño ocasionados. Será la ordenanza local la encargada de decidir la gradación de la intensidad con que se afecta a la convivencia, el patrimonio o los servicios públicos locales y luego atribuirle el carácter de infracción leve o grave sin más límites que los estipulados para las infracciones muy graves. Ello supone que en su determinación habrá que ponderar elementos tales como la cuantía del daño, el número de afectados, repercusiones de la acción o la

12 Por todos, Lasagabaster Herrarte, I., “La potestad sancionadora local en la Ley 57/2003, de medidas para la modernización del gobierno local”, Revista Vasca de Administración Pública, n 68, 2004, pág. 175 y ss. 
fuerza o energía de la perturbación para calificar la conducta en una de estas dos categorías ${ }^{13}$.

Para finalizar, el art. 141 LBRL prevé los tipos y graduaciones de la sanciones posibles. Establece como único tipo de sanción la multa y determina las cuantías máximas según el tipo de infracción que abarcan desde los 750 euros para la leves, 1500 para las graves y 3000 para las muy graves.

El círculo se cierra con la modificación de la LRJ-PAC que, como es sabido es de aplicación a los entes locales y que incorpora a los art. 127 y 129 de la misma un inciso en el que se remite en materia de legalidad sancionadora a lo dispuesto por el presente Título de la LBRL.

\section{CRÍTICAS Y CONTRACRÍTICAS AL MODELO SANCIONADOR LOCAL}

Las críticas vertidas contra estos preceptos se centran en su mayoría en el excesivo margen dejado a la potestad reglamentaria local. $O$, mutatis mutandis, en la laxitud y falta de contenido sustancial con que se describen las conductas sancionables y la permanente apelación a conceptos jurídicos indeterminados. Se ha dicho que esta manera de definir los hechos no cumple con la exigencia de la predeterminación de comportamientos o la taxatividad en la concreción legal y en la tipificación de las conductas. Se trata de un cheque en blanco que permite incorporar vía ordenanzas un número indeterminado de infracciones, distintas entre sí en cuanto a contenido y alcance, en contra del principio de seguridad jurídica ${ }^{14}$.

Se denuncia, además, la abdicación relativa que se hace del principio de legalidad sancionadora y lo que esto supone de cara a la protección de la libertad de los ciudadanos así como de la alarmante heterogeneidad provocada que conduce a la creación de al menos tantos regímenes jurídicos sancionadores como ayuntamientos españoles hay. Así, comenta Gallardo Castillo, esta situación puede abocar en ordenanzas del más diverso contenido o en paradojas tales como que una misma conducta pueda ser considerada como infracción en un término municipal mientras que en el colindante puede gozar de una situación de cómoda impunidad¹5.

\section{Sobre la heterogeneidad normativa}

Sin embargo, la situación no nos parece tan dramática como inicialmente aparenta. De entrada, la heterogeneidad normativa ya se manifiesta en el nivel autonómico y

13 Sanz Gandasegui, cit., pág. 689.

14 Gallardo Castillo, M. J., cit., págs. 84 a 86. También y en general,se ha calificado a esta normativa de "excesivamente genérica e insuficiente, de suerte que no contiene amparo bastante para la inmediata $248 \quad$ intervención tipificadota 
no por ello se reclama la titularidad única estatal del poder de coacción. Es más, la diversidad y heterogeneidad es el distintivo de los Estados descentralizados y el elemento coadyuvante de un desarrollo acorde con las necesidades de cada tiempo y lugar.

Tampoco se genera mayor inseguridad jurídica por el hecho de ceder el ejercicio pleno de la potestad sancionadora a los entes territoriales subestatales porque la protección de la esfera jurídica de los ciudadanos no depende del uso del poder político y administrativo legalmente atribuido para la consecución de los intereses de la comunidad a la que representan sino del adecuado control del mismo.

Si lo personalizamos en los entes locales, la situación no tiene por qué empeorar. Antes bien, admitido que la potestad sancionadora es un elemento consustancial a las tareas de gobierno y por lo tanto manejado por todo el espectro institucional administrativo, territorial o no; admitido, también, que la uniformidad en el ejercicio de la potestad sancionadora no es equivalente a mayor seguridad jurídica ni a garantía del buen uso de esta potestad; y finalmente, que cada entidad local tiene su propia problemática, sus concretas circunstancias y peculiaridades que la llevan a distinguirse de la otra y a perseguir unas políticas públicas propias, por qué la potestad sancionadora va a quedar encorsetada a un esquema uniformista y unitario en un Estado que promueve la variedad y la diversidad normativa. No son lo mismo las necesidades de un gran municipio que las de un pequeño municipio de cara a garantizar la convivencia ciudadana, por ejemplo. Como tampoco son iguales las características de un municipio turístico frente a un municipio agrícola o industrial. Ni son lo mismo las necesidades punitivas de una entidad preocupada por ofrecer a sus ciudadanos unas ciudades confortables con unos buenos servicios y un buen mobiliario urbano que aquél totalmente despreocupado por estas cuestiones. Si como es cierto, la autonomía local supone la capacidad de darse una dirección y gobierno político-administrativo propio y adecuado a las necesidades colectivas demandadas ejerciendo para ello potestades de mayor calado que la sancionadora (piénsese en las potestades anejas a la función urbanística), debe ser también posible que un Ayuntamiento pueda ejercer el poder sancionador de acuerdo con los intereses perseguidos.

\section{Sobre la legalidad formal}

Lo dicho no nos conduce, en un segundo orden de cuestiones, a negar la necesidad de preservar la legalidad sancionadora recogida en el art. 25 CE pero sí a interpretarla cabalmente de acuerdo con el reparto del poder territorial. Hoy en día asistimos a numerosas muestras del ejercicio del poder punitivo local que tras un aparente respeto a la reserva legal cobijan numerosas desviaciones del principio. Ya en su momento Trayter $^{16}$ puso de manifiesto algunas patologías del sistema: leyes sectoriales auto-

16 Trayter Jiménez, J.M., "Protección del medio ambiente. Sanciones administrativas y competencias locales", en Derecho del medio ambiente y administración local (Esteve Pardo coord..), Cívitas, Madrid, 1995, págs. 552 y ss. 
nómicas y estatales que obvian absolutamente las competencias y responsabilidades de los entes locales en un determinado sector o simplemente desconocen el alcance que su regulación provoca en el ámbito local, dejando a la deriva la función de gobierno de nuestros municipios. Leyes que regulan el ejercicio de la potestad sancionadora local en términos tan o más genéricos que los ahora establecidos en la LBRL y que han servido, por razones de auténtica supervivencia del sistema, de cubierta legal a los más variados tipos de infracciones locales. Y ordenanzas que tipifican infracciones y sanciones en ámbitos cuya necesidad no puede cuestionarse, y que sin embargo se ven arrastradas por la acción y omisión del legislador autonómico o estatal, a dictarlas sin ningún amparo legal.

Si nos acercamos a la casuística, abundan los supuestos en los que las ordenanzas omiten cualquier referencia expresa a la Ley que teóricamente están desarrollando cuando regulan su poder punitivo mientras otras intentan encajar el régimen sancionador en leyes que difícilmente le pueden dar cobertura. Y desde el otro ángulo, no faltan ejemplos de leyes que no prevén las conductas tipificables en el ámbito local o ignoran las competencias locales en ese concreto sector.

Todo ello deja traslucir que el sistema actual no es en absoluto perfecto. Esa imperfección se manifiesta incluso cuando el amparo legal es teóricamente existente y la norma local se limita a ser un desarrollo reglamentario de la Ley formal. La predeterminación total de las conductas susceptibles de represión sancionadora es una tarea que difícilmente es capaz de cumplir por sí solo el legislador estatal o autonómico porque la casuística local es mucho más rica y abundante de lo que aquél presume. Por eso, la tarea tipificadota debe ser fruto de la colaboración efectiva de ambos y no patrimonio de uno sólo.

Por lo demás, es evidente que el mantenimiento de una situación en los términos que se ha venido haciendo hasta ahora, conduce a un mayor incremento de la quiebra del principio de legalidad sancionadora. La solución no radica, por tanto, en tensar la cuerda hacia un lado sino en buscar el equilibrio de fuerzas. Los caminos hacia la solución se interseccionan: o bien se concede un estatus cuasi de ley a la norma local, significadamente a la ordenanza, o bien se relaja el sistema, se "flexibiliza" siguiendo la terminología del Tribunal Constitucional, para el ámbito local de modo que se permita un papel más activo a la ordenanza en tanto que reglamento. No caben más alternativas.

Si como parece, éste último camino es el seguido por jurisprudencia y legislación, la solución del actual Título XI de la LBRL parece un buen remedio aunque de eficacia reducida.

No encontramos pues, ninguno de los inconvenientes que se vinieron apuntando desde otros frentes doctrinales. El contenido actual de la LBRL en este punto nos parece prudente y garantizador de los principios puestos en cuestión. La autonomía 250 es un ejercicio responsable de la libertad y ello significa que tanta fe y confianza pue- 
de ponerse en el legislador local como en el legislador autonómico y estatal. Diríase más, no se puede exigir un cumplimiento responsable a los actores políticos locales en la ordenación y gestión de los asuntos que interesan a la comunidad y al mismo tiempo impedir tal cumplimiento. Ofrecer al ámbito local un margen razonable y generoso de normación y aplicación de la potestad sancionadora es en sí mismo un ejercicio de madurez y afirmación del sistema organizativo español.

Así pues, en el aspecto formal, el principio de reserva de ley se ve salvado por la actual regulación que efectúa la LBRL. Como dice el Tribunal Supremo, "la posibilidad de tipificar mediante Ordenanza local infracciones y sanciones de carácter pecuniario tienen hoy plena cobertura legal en virtud de lo dispuesto en el Título XI de la Ley 57/2003" (STS de 20 de diciembre de 2007, FJ5). Y de forma más precisa, se apunta que "con la nueva regulación el principio de legalidad en materia sancionadora en el ámbito normativo de las Corporaciones locales ha pasado de necesitar una específica vinculación positiva, es decir, una participación del legislador sectorial (estatal o autonómico) con la tipificación de las infracciones y sanciones para que los entes locales puedan imponer sanciones, a una vinculación negativa que implica que las Administraciones locales podrán imponer sanciones siempre que respeten el contenido establecido en los nuevos artículos 140 y ss de la citada LBRL y en la legislación sectorial” (STSJ Castilla y León 2247/2006, de 15 de diciembre, FJ 2).

\section{Sobre la legalidad material}

Resta, por tanto, analizar si esto también se cumple respecto de la garantía material que efectúa la LBRL. Para ello, conviene retomar aquí las palabras del Tribunal Constitucional cuando apunta que la flexibilidad implica al menos dos órdenes de cosas: dar un amplio margen a la regulación municipal; y no ser exigible una definición de cada tipo de ilícito y sanción en la ley. Las exigencias del art. 25 CE se limitan en este punto a diseñar una ley que simplemente establezca los criterios que orienten y condicionen la valoración de cada municipio a la hora de establecer los tipos de infracción y, en lo relativo a las sanciones, basta con establecer una relación de las posibles sanciones que cada ordenanza pueda predeterminar en función de los ilícitos administrativos que ella misma tipifica.

Pues bien, como bien indica alguna jurisprudencia "el nuevo art. 140 LBRL clasifica las infracciones que pueden ser muy graves, graves y leves, relacionando hasta seis supuestos de infracciones muy graves que van más allá de la orientación en la valoración de antijuridicidad, pues pueden tenerse de verdaderas descripciones de conductas infractoras o tipos" (STSJ Valencia, 551/2007, de 1 de marzo, FJ 7).

Por otra parte, el hecho de que no se determinen con la misma minuciosidad las conductas graves y leves sino per relationem dejando la decisión final al ente local previa valoración del grado de intensidad, tampoco menoscaba la legalidad material pues se trata de una práctica que igualmente adoptan otras muchas leyes sectoria- 
les y que la jurisprudencia ha dado por bien actuada ${ }^{17}$. Se recuerda sobre este extremo que la Ley Orgánica de Protección de la Seguridad Ciudadana establece en el art. 26.j) una regla residual de similar factura según la cual se calificaban como infracciones leves cualesquiera incumplimientos de obligaciones o vulneraciones de prohibiciones establecidas en la propia Ley y sobre la que tuvo ocasión de pronunciarse el Tribunal Constitucional diciendo que nada cabe reprochar pues, "siendo como es una norma residual y de remisión, la delimitación precisa de las conductas sancionables corresponderá a las reglas remitidas, configuradoras de las obligaciones y prohibiciones, cuya conculcación dará lugar a la infracción" (STC 341/1993, de 18 de noviembre, FJ 10).

No hay que olvidar, además, que aunque la apreciación se haga depender de un concepto jurídico indeterminado como es la intensidad, no le resta validez ya que constituye doctrina consolidada del Tribunal Constitucional la posibilidad utilizar dichos conceptos siempre que su concreción sea razonablemente factible en virtud de criterios lógicos, técnicos o de experiencia, de tal forma que permita prever, con suficiente seguridad, la naturaleza y las características esenciales de las conductas constitutivas de la infracción tipificada (STC 151/1997, de 29 de septiembre, FJ 9).

Lo mismo puede predicarse de las sanciones previstas en el art. 141 LBRL donde además de contemplarse sólo un tipo, la multa, se establece una escala de máximos. Datos suficientes dada la innecesariedad sentada por el Tribunal Constitucional de establecer una clase específica de sanciones para cada grupo de ilícitos.

Tal circunstancia no se compadece del hecho de que la ordenanza deba obedecer escrupulosamente el principio de tipicidad. Éstas tienen el deber de cumplir con el requisito de lex certa, esto es, cumplir la exigencia de predeterminación normativa de las conductas ilícitas y de las sanciones correspondientes. Lo que hace recaer sobre el legislador local la obligación de configurarlas con la mayor precisión posible para que los ciudadanos puedan conocer de antemano el ámbito de lo proscrito y prever las consecuencias de sus acciones. (STSJ Castilla y León 2247/2006, de 15 de diciembre, FJ 4). De ahí que no se admitan redacciones genéricas e indeterminadas utilizando fórmulas tales como "el incumplimiento de las obligaciones establecidas en la presente ordenanza constituirá infracción administrativa” pues tales cláusulas habrán de tenerse por vulneradoras del principio de tipicidad que exige "que se definan con precisión y claridad las conductas constitutivas de infracción, lo cual no se logra con una reseña tan genérica" (STSJ Andalucía 416/2008, de 31 de marzo, FJ 11).

17 Así, el art. 237.3 del Decreto Legislativo 2/2003, de 28 de abril, por el que se dicta el Texto refundido de la Ley Municipal y de Régimen Local de Cataluña establece un régimen tipificador prácticamente en blanco: "Si las leyes no establecen un régimen específico, pueden imponerse multas por infracción de las ordenanzas locales, las cuales no pueden exceder de 1.803,04 euros en municipios de más de 250.000 habitantes, de 901,52 euros en los de 50.001 a 250.000 habitantes, de 450,76 euros en los de 20.001 a 252 municipios. 
$\mathrm{Ni}$ tampoco que la ordenanza se limite a reproducir los contenidos del art. 140 LBRL elevándolos a la categoría de tipo infractor pues la generalidad y ambigüedad de aquél impiden prever con el suficiente grado de seguridad la naturaleza y características esenciales de las conductas sancionables.

Y lo mismo puede decirse de la imposición de sanciones que, además de estar debidamente predeterminadas en la ordenanza local, deben acomodarse al principio de proporcionalidad y graduación que impide, entre otras cosas, imponer la misma sanción a todos los tipos de infracciones integrados en una misma categoría (STSJ Comunidad Valenciana 336/2006, de 20 de febrero, FJ 2). Asimismo, no ha de olvidarse que la "resolución sancionadora que no exprese la tipicidad que le sirve de base, sea porque no lo hace en absoluto, sea porque lo hace de un modo equivocado", infringe el art. 25.1 CE (STC 113/2008, de 29 de septiembre, FJ 4).

La norma punitiva local debe, en suma, predecir con suficiente grado de certeza las conductas que constituyen infracción y el tipo y grado de la sanción del que puede hacerse merecedor quien la cometa, lo que conlleva que no quepa constitucionalmente admitir formulaciones tan abiertas por su amplitud, vaguedad o indefinición, que la efectividad dependa de una decisión prácticamente libre y arbitraria del intérprete y juzgador (STC 100/2003, de 2 de junio, FJ 3).

Consecuentemente, corresponde a la ordenanza sancionadora el deber de hacer el "máximo esfuerzo posible" para garantizar la seguridad jurídica (STC 62/1982, de 15 de octubre, FJ7) definiendo la conducta y el elemento subjetivo del propósito directo del sujeto de realizar la conducta infractora dentro de los límites impuestos por la LBRL.

\section{ALGUNAS CUESTIONES SOBE EL ACTUAL EJERCICIO DE LA POTESTAD SANCIONADORA LOCAL}

Ciertamente, la actual legislación de la potestad sancionadora local ha experimentado un avance importante con la introducción de esta modificación legislativa pero aún así no consigue colmar todas las necesidades de los entes locales.

La primera de ellas hace referencia al ámbito de aplicación. Como bien ha puesto de relieve alguna doctrina, esta reforma sólo abarca unas materias limitadas y un tipo de sanción concretos, lo que la hace pecar de "excesivamente genérica e insuficiente, de suerte que no constituye amparo bastante para la inmediata intervención tipificadota de las ordenanzas locales"18. La jurisprudencia actual nos ofrece alguna muestra. La conducta de no proteger los cruces de calzada en las obras de vía pública conforme a lo establecido en la ordenanza, no encaja en ninguno de los supuestos

18 García Gómez de Mercado, cit., pág. 45. 
previstos en el art. 140 LBRL (STSJ Madrid 1331/2005, de 13 de octubre, FJ 7) ${ }^{19}$, como tampoco la obligación de utilizar vallas de modelos definidos en una ordenanza, Igualmente, el establecimiento de medidas punitivas en materia de estiércol, purines y fangos de depuradoras que, a falta de norma sectorial expresa, tampoco puede "encuadrase en la ordenación de las relaciones de convivencia de interés local ni en el uso de los servicios que se especifican, por lo que esta aparentemente genérica cobertura legal, no es suficiente" (STSJ Cataluña 358/2008, de 5 de mayo, FJ 7).

A lo dicho hay que añadir que, de acuerdo con las normas sancionadoras deben ser objeto de una interpretación estricta, no extensiva ni analógica in malam partem, ${ }^{20}$ lo que reduce aún más el ámbito de aplicación. No obstante, como luego veremos al analizar una sentencia reciente del Tribunal Supremo, la garantía de la autonomía local debe imponerse una vez más a la hora de interpretar esta potestad y abrir caminos antes que cerrarlos.

En materia de sanciones también resulta problemática la introducción de algunas medidas económicas paralelas por carecer de respaldo normativo. Es el caso de la imposición de fianzas o la exigencia de seguros de responsabilidad civil para cubrir los posibles riesgos que se deriven del desarrollo de actividades. Este requisito implica disposición patrimonial del particular y únicamente puede tener lugar en el caso de contar con la cobertura legal suficiente. Dado que la actual LBRL no prevé como medida sancionatoria este presupuesto, tal disposición en una ordenanza dictada al amparo de los preceptos estudiados de la LBRL deberán declararse nulos (STSJ Andalucía 416/2008, de 31 de marzo, FJ 11).

Y lo mismo, con más razón, puede predicarse de aquellos supuestos en los que las ordenanzas sancionadoras imponen tasas encubiertas por la utilización de un servicio público, (por ej., responder del importe de los trabajos de limpieza de las vías y espacios públicos que se deriven de un acto de los particulares) pues carecen de amparo legal tanto desde el punto de vista de la actual legislación sancionadora como desde el punto de vista tributario si no existe una ordenanza fiscal que lo recoja. (STSJ Castilla y León 2247/2006, de 15 de diciembre, FJ 3).

Otra cuestión no menos importante es la convalidación de las ordenanzas anteriores a la reforma, esto es, las dictadas con anterioridad al 1 de enero d 2004. Sobre este tema, Domenech Pascual ya señalaba que ante la ausencia de una disposición legal expresa en la LBRL que habilite su propia retroactividad, sólo cabe entender la misma de manera implícita siempre que así lo imponga claramente la finalidad de la nueva norma y su voluntad sea, aunque tácita, inequívoca. Lo que le llevó a entender, no sin ciertas dudas, que la Ley 57/2003 no tiene el efecto convalidante de las orde-

19 En este mismo sentido las SSTSJ Madrid 835/2005, de 21 de junio y 584/2005, de 5 de mayo, $104 / 2005$, de 28 de enero, entre otras

20 Vid. Domenech Pascual, G., "La tipificación de infracciones y sanciones por las entidades loca-

254 les", Revista General de Derecho Administrativo, n 6, 2004. También en base de datos IUSTEL, pág. 16. 
nanzas dictadas con anterioridad a enero de 2004 ni siquiera con efectos jurídicos a partir de esa fecha ${ }^{21}$.

Estas mismas dudas se reflejan en la jurisprudencia ya que mientras algunas sentencias aluden al Título XI de la LBRL para apoyar la legitimación de una ordenanza aprobada con anterioridad a la reforma (STSJ Comunidad Valenciana 336/2006, de 20 de febrero, FJ3), otras niegan el carácter retroactivo de esta disposición y el efecto convalidante del citado Título. Así, se estima que cuando la ordenanza "sea de fecha anterior a la entrada en vigor de la Ley 57/2003 y conforme al artículo 9 de la Constitución que garantiza la irretroactividad de las disposiciones sancionadores y restrictivas de los derechos individuales entre los que se encuentran los contenidos en el artículo 25, pues se trata de un derecho fundamental", no cabe convalidación.(STSJ Madrid 1331/2005, de 13 de octubre, FJ 6). Por su parte, el Tribunal Supremo a la hora de abordar la legalidad de una ordenanza sancionadora anterior a la reforma, obvia cualquier fundamentación sobre el Título XI de la LBRL aunque no ignora su existencia, poniendo así de manifiesto la ausencia del efecto convalidante ${ }^{22}$.

Esta situación nos reconduce a las denominadas coberturas legales ex post facto. En principio, las coberturas legales son admisibles cuando existe colaboración normativa ley-reglamento de modo que la aparición posterior de una ley hace que ese reglamento quede sanado y se convalide desde que la ley de cobertura entra en vigor. Si a ello unimos la obligación de buscar una cobertura legal a cualquier precepto reglamentario, incluso aunque no se cite en el reglamento o éste se incline por otra, parece evidente que la aparición de la reforma objeto de análisis podría sanar muchas de las infracciones recogidas en ordenanzas que en la actualidad carecen de amparo legal.

El único requisito exigido es que en el momento de la comisión de la infracción exista un texto legal que le de cobertura legal. Así lo establece el Auto de 19 de mayo de 2003:

"Los hechos imputados al recurrente y por los que se le ha impuesto la sanción [... ] han tenido lugar con posterioridad a la entrada en vigor de la meritada ley autonómica. Frente a lo que de contrario aduce el recurrente, hemos de convenir en que esta norma ha venido a dotar de cobertura legal a la Ordenanza municipal en la definición del tipo y la previsión de la sanción correspondiente" (FJ 9).

Consiguientemente, el efecto sanador o convalidante tendrá carácter limitado ya que "lo será sólo respecto de las infracciones que se cometan a partir de ese momento, pues otra cosa sería aplicar retroactivamente una disposición sancionadora”23

21 Domenech Pascual, G., cit, pág. 19.

22 Así, STS de 20 de diciembre de 2007.

23 Vid. González Tobarra, P., "El principio de legalidad: los principios de reserva de ley, irretroactividad y tipicidad” en Manual de Derecho Administrativo sancionador, (De Fuentes Bardají, dir), Ministerio de 
Una alternativa para superar este problema en su globalidad sería que otras leyes, estatales o autonómicas, dispusiera una previsión de este signo y de este modo evitar los efectos antieconómicos y burocráticos que derivan de la falta de convalidación de muchas ordenanzas que por su contenido bien pudieran abrigarse bajo el actual paraguas local.

Al hilo de esto conviene también recordar que la LBRL no mantiene el monopolio de la habilitación legal para el ejercicio de la potestad sancionadora local puesto que "no ocupa en nuestro Ordenamiento una posición distinta a las demás leyes ordinarias del Estado que puedan por tanto establecer disposiciones contrarias a la Ley de bases del régimen local, las cuales deberán ser consideradas modificaciones legislativas pero no Leyes inconstitucionales". Y respecto a las leyes autonómicas, sólo podrá ser canon de validez "en aquellos aspectos enrraizables directamente en los arts. 137,

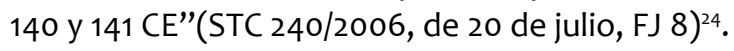

\section{UN PASO MÁS HACÍA EL RECONOCIMENTO DE LA AUTONOMÍA LOCAL: LA STS DE 20 DE DICIEMBRE DE 2007. EL PODER DE NORMACIÓN Y LA POTESTAD IMPLÍCITA DE SANCIÓN}

Como se ha ido viendo, hablar de potestad sancionadora local supone aún al día de hoy retomar un tema inconcluso cuya articulación sigue estando bañada de cierta problemática. Ciertamente, las aportaciones doctrinales y jurisprudenciales han propiciado con gran atino que esa mentada flexibilidad del sistema se tradujese al menos en una primera rotura de cadenas dogmáticas en beneficio de nuestros entes locales.

En esta línea de emancipación del régimen local se sigue trabajando denodadamente. Uno de los últimos frutos jurisprudenciales, al que nos referiremos seguidamente, constituye un paradigma de esta tendencia.

La sentencia del Tribunal Supremo de 20 de diciembre de 2007 representa un ejercicio de apoderamiento local. En ella se resuelve un recurso de casación contra la sentencia dictada con fecha de 18 de febrero de 2002 por el Tribunal Superior de Justicia de Aragón en el recurso contra modificación de una ordenanza fiscal dictada por el Ayuntamiento de Zaragoza.

Dicha ordenanza establece una serie de infracciones y sanciones para asegurar la adecuada utilización de sus bienes y la defensa de su patrimonio. A la cuestión de

Justicia-Thomson Aranzadi, Navarra, 2005, pág. 154. En este mismo sentido la STC 132/2001, de 8 de junio cuando busca la cobertura legal a la sanción impuesta en aplicación de la ordenanza de 1979 en una Ley de 1987.

24 Sobre el papel de la LBRL frente a otras legislaciones, estatales y autonómicas, vid. Fuentetaja 256 yastor, J., “Autonomía local y legislación básica”, en en Reforma y retos de la Administración Local (Parada 
qué sucede cuando las ordenanzas contienen mandatos dirigidos a los habitantes y vecinos pero luego no pueden normar la situación producida si se incumple la ordenanza, la contestación no puede ser más categórica: la potestad sancionadora es un poder implícito en el poder normativo. Y para ello se apoya en los arts. 55 y 59 TRRL.

El fallo judicial sienta dos órdenes de cuestiones en el fundamento jurídico tercero. De una parte, la minusvaloración que se ha hecho de los referidos artículos del TRRL; y de otra, el menoscabo de la autonomía local provocado por la deficiencia de un sistema jurídico que devalúa el poder normativo local.

Tras relatar la conocida doctrina del Tribunal Constitucional que, aunque "pueda merecer serios reparos" debe acatarse, señala que su aplicación al ámbito local lleva a un resultado absurdo como es que "las Ordenanzas locales resultan inaplicables y la potestad reglamentaria menoscabada y disminuida cuando, aún tratándose de materias de estricta competencia local, no existe Ley habilitante para tipificar las infracciones y sanciones".

Frente a esta argumentación el Tribunal Supremo se detiene en analizar los contenidos mínimos de toda norma jurídica: "para que estemos ante una verdadera norma jurídica, con su triple contenido de mandato, organización social y disciplina de las relaciones jurídicas, es indispensable que exista una garantía de la normativa correspondiente". Dentro de éstas "ha de convenirse que la principal garantía está constituida por la posibilidad de imponer sanciones, o en su caso penas, en los casos de incumplimiento de las normas. En el campo del Derecho público la posibilidad de imponer una sanción por conducta ilícita es lo que dota de contenido a una de las más típicas potestades de las autoridades administrativas, como es la potestad reglamentaria".

Llevado el razonamiento a sus últimas conclusiones, "resulta cierta la afirmación de que un Reglamento (en nuestro caso una Ordenanza local) que puede, sin ninguna consecuencia, ser incumplido por los ciudadanos a los que todo está permitido en la materia es una norma reglamentaria sin fundamento ni garantía y por tanto susceptible de quedar sin efectos".

Lo dicho debe a su vez conectarse con el principio de autonomía local que supone entre otras cosas "tener una capacidad efectiva", esto es, poder para "ordenar al menos una parte de los asuntos públicos". Por lo tanto, declara el Tribunal Supremo con toda lógica, el menoscabo del poder de sanción implica un menoscabo de la capacidad efectiva de ordenación:

"Parece claro que si se otorga la potestad reglamentaria a las entidades locales, sin duda para ordenar los asuntos públicos de su competencia, y no se deduce ninguna consecuencia jurídica del incumplimiento de aquella ordenación, los supuestos titulares de la potestad reglamentaria, en este caso los entes locales, no tienen una capacidad efectiva de llevar a cabo la ordenación, Una norma que puede 
incumplirse sin consecuencia alguna carece por completo de efectividad. Por ello, si es ésta la situación se está ante una disminución de la autonomía local contraria al precepto de la Carta".

Sentado pues que cualquier merma de la potestad reglamentaria de los entes locales es un ataque frontal a la autonomía local, el Tribunal Supremo no se detiene en este extremo sino que apela al carácter democrático de la Ordenanza para revalidad su idoneidad como instrumento ordenador de la potestad sancionadora. Dice su fundamento cuarto:

"Por lo demás, difícilmente podría tacharse esta solución de antidemocrática, pues los miembros de la Corporación local que aprobaron la Ordenanza han sido elegidos democráticamente. Esta consideración no carece ni mucho menos de interés. Pues los destinatarios de la Ordenanza loca tipificadota de infracciones y sanciones son las personas del municipio y, en su caso, los entes establecidos en él y son aquellas personas las que han elegido a los miembros del Pleno del Ayuntamiento que aprueba la Ordenanza. Se da por tanto una situación análoga a la aprobación de una Ley por los parlamentarios elegidos por la población del Estado o de una Comunidad Autónoma. Por ello la solución que supone nuestra interpretación se atiene a los principios democráticos que inspiran nuestro ordenamiento".

Todo ello conduce a una única solución: “hay que atenerse a la solución jurisprudencial más favorable a la autonomía municipal que consagran los arts. 137 y 140 de la Constitución, los cuales deben ser interpretados de acuerdo con el art. 3.1 de la Carta Europea de la Autonomía local”.

En cuanto al alcance de ese poder de sanción, basta con acogerse a lo previsto por los arts. 55 y 59 TRRL que tan poco se han tenido en cuenta y que, sin embargo, constituyen un marco básico de regulación:

\footnotetext{
"Debemos declarar que mediante Ordenanza local, en cumplimiento de los preceptos generales de los arts. 55 y 59 del Texto refundido de régimen local, se pueden tipificar válidamente las infracciones y sanciones, que han de ser de carácter pecuniario, cuando ello sea una garantía indispensable para su cumplimiento, siempre que al hacerlo no se contravengan las leyes vigentes y únicamente en los casos en que no se haya promulgado una Ley estatal o autonómica sobre la materia y en los que los Ayuntamientos actúen en ejercicio de competencias propias que, por así decirlo, tengan el carácter de nucleares y lleven anejas potestades implícitas de regulación, y respetando los principios de proporcionalidad así como ponderando la gravedad del ilícito y teniendo en cuenta las características del ente local".
}

En definitiva, este fallo jurisprudencial se viene a unir a esa corriente del Tribunal Supremo que ya desde el año 2003 aboga por crear un espacio propio y singular para la ordenanza sancionadora pero que ahora introduce un plus cual es maximizar el campo de aplicación de ésta. Por tanto, cualquier ordenación de bienes, servicios o relaciones de convivencia locales que impliquen una actividad de normación local o 
cuando tratándose de competencias compartidas el ente superior no haya hecho uso de la potestad legislativa con esta finalidad, debe entenderse que existe un poder implícito para sancionar a favor de los entes locales. En el buen entendimiento de que se ejerza una competencia típica, no se infrinjan la legislación en vigor y se trate de sanciones de carácter pecuniario.

Sin lugar a dudas, es una necesidad social y jurídica otorgar a los entes locales la posibilidad de reacción frente al incumplimiento de ordenanzas que han sido dictadas en el ejercicio válido de la potestad reglamentaria que las leyes le otorgan.

\section{LA CONCRETA ATRIBUCIÓN DE LA POTESTAD SANCIONADORA EN EL ÁMBITO LOCAL}

La potestad sancionadora atribuida a los entes locales por el art. 4.1.f) LBRL deberá ejercerse por los órganos que la tengan expresamente atribuida. Ello, sin perjuicio de que, como se dijo, la elaboración de la concreta ordenanza es una competencia exclusiva de los Plenos locales.

En el ámbito municipal, el art. 21.1.n) LBRL atribuye al Alcalde la competencia para sancionar las faltas de desobediencia a su autoridad o por infracciones de las ordenanzas municipales salvo en los casos en que tal facultad esté atribuida a otras instancias.

Igualmente permite la delegación del ejercicio de esta competencia (art. 21.3 LBRL) en la Junta de Gobierno local y en los Tenientes de Alcalde (art. 23.4 LBRL).

En el caso de los municipios de gran población, la potestad sancionadora se atribuye a la Junta de Gobierno Local (art. 127.I LBLRL) y contrariamente a lo dispuesto para el Alcalde, se prohíbe la delegación (art. 127.2 LBRL).

En el ámbito provincial, será el Presidente de la Diputación quien ostente el ejercicio de la potestad sancionadora de acuerdo con el art. 34.1.o) LBRL que le asigna como cláusula de cierre el ejercicio de aquellas otras atribuciones que la legislación del Estado o de las Comunidades Autónomas asigne a la Diputación y no estén expresamente atribuidas a otros órganos. Al igual que en el caso del Alcalde, el Presidente puede delegar el ejercicio de sus atribuciones en la Junta de Gobierno local (art. 35 LBRL).

Este mismo régimen se aplica a los Consejos insulares de las Islas Baleares (art. 41.3 LBRL). A los Cabildos insulares Canarios, sin embargo, les será de aplicación lo dispuesto para los municipios de gran población (art. 41.1 en relación con al Disposición adicional decimocuarta LBRL). 
